\title{
Exchange transfusion in newborn infants: effects on granulocyte function
}

\author{
B. PELET
}

Service de Pédiatrie, Centre Hospitalier Universitaire Vaudois, Lausanne, Switzerland

SUMMARY During 23 exchange transfusions, the granulocytes from 27 donors and 16 newborn infants were tested for opsonic activity and granulocyte function by the nitrobluetetrazolium test. Granulocyte function in a newborn baby receiving an exchange transfusion can be altered positively or negatively, depending on the quality of the donor's blood. If exchange transfusion is used in the management of neonatal sepsis, special attention should be given to the immunological properties of the donor blood.

Studies have shown the sometimes strikingly beneficial results from blood exchange transfusion (ET) in neonatal septicaemia with sclerema (Prod'hom et al., 1974; Torrado et al., 1974; Xanthou et al., 1975). These results have been

Service de Pédiatrie, Centre Hospitalier Universitaire Vaudois, Lausanne

B. PELET, chief resident in paediatrics attributed to various mechanisms-such as the mobilisation of bone marrow leucocytes (Xanthou et al., 1973), or a rise in serum opsonic activity (Davis et al., 1971). We tested granulocyte function by the nitrobluetetrazolium (NBT) test (Rubinstein and Pelet, 1973), and opsonic activity (Soothill and Harvey, 1976), before, during, and immediately after ET.

Table Granulocyte function in 16 infants given exchange transfusions

\begin{tabular}{|c|c|c|c|c|c|c|c|c|}
\hline Case & $\begin{array}{l}\text { Gestational } \\
\text { age (weeks) }\end{array}$ & $\begin{array}{l}\text { Birthweight } \\
(g)\end{array}$ & Diseases & $\begin{array}{l}\text { Age at ET } \\
\text { (hours) }\end{array}$ & $\begin{array}{l}\text { Neutrophils } \\
\times 10^{9} / l\end{array}$ & $\begin{array}{l}\text { Bands/ } \\
\text { segmented } \\
\text { neutrophils }\end{array}$ & $\begin{array}{l}\text { Opsonisation } \\
\text { index }\end{array}$ & $\begin{array}{l}\text { NBT after } \\
\text { maximum } \\
\text { stimulation }\end{array}$ \\
\hline $\begin{array}{r}1 \mathrm{a} \\
\mathrm{b} \\
\mathrm{c}\end{array}$ & $\begin{array}{l}31 \text { (Small- } \\
\text { for-dates) }\end{array}$ & 1160 & $\begin{array}{l}\text { Escherichia coli septicaemia and } \\
\text { meningitis, sclerema (and death) }\end{array}$ & $\begin{array}{l}20 \\
27 \\
81\end{array}$ & $\begin{array}{l}1 \cdot 3 \\
3 \cdot 8 \\
4 \cdot 7\end{array}$ & $\begin{array}{l}6 \cdot 6 \\
2 \cdot 5 \\
0 \cdot 8\end{array}$ & $\begin{array}{l}3 \cdot 8 \\
3 \cdot 7 \\
4 \cdot 2\end{array}$ & - \\
\hline $\begin{array}{r}2 \mathrm{a} \\
\mathrm{b}\end{array}$ & 36 & 2100 & E. coli septicaemia, sclerema & $\begin{array}{l}35 \\
49\end{array}$ & 0.5 & $2 \cdot 1$ & $\begin{array}{l}1 \cdot 4 \\
3 \cdot 9\end{array}$ & $\begin{array}{l}96 \\
92\end{array}$ \\
\hline $\begin{array}{l}\text { c } \\
\text { d }\end{array}$ & & & & $\begin{array}{l}61 \\
72\end{array}$ & $\begin{array}{l}1 \cdot 4 \\
2 \cdot 4\end{array}$ & $\begin{array}{l}0.9 \\
1.4\end{array}$ & $\begin{array}{l}3 \cdot 2 \\
4 \cdot 5\end{array}$ & $\begin{array}{l}95 \\
68\end{array}$ \\
\hline $\begin{array}{r}3 \mathbf{a} \\
\mathbf{b}\end{array}$ & 32 & 1710 & Sclerema & $\begin{array}{r}36 \\
125\end{array}$ & $\begin{array}{l}3 \cdot 4 \\
4 \cdot 5\end{array}$ & $\begin{array}{l}3 \cdot 0 \\
0 \cdot 4\end{array}$ & $\begin{array}{l}2 \cdot 0 \\
4 \cdot 4\end{array}$ & $\begin{array}{l}52 \\
24\end{array}$ \\
\hline 4 & 40 & 2760 & Staphylococcus aureus septicaemia & 60 & $1 \cdot 5$ & $2 \cdot 1$ & $6 \cdot 2$ & 98 \\
\hline 5 & 33 & 2430 & IS, neonatal asphyxia, HMD & 20 & $2 \cdot 3$ & $1 \cdot 3$ & 1.95 & 96 \\
\hline 6 & 33 & 1740 & IS, HMD & 60 & $3 \cdot 0$ & 0.6 & $5 \cdot 0$ & 93 \\
\hline 7 & 33 & 1560 & IS, HMD & 49 & $1 \cdot 2$ & 1.4 & $6 \cdot 3$ & 80 \\
\hline $\begin{array}{r}8 \mathbf{a} \\
\mathbf{b}\end{array}$ & 37 & 2910 & IS, $\mathbf{R h}$ incompatibility & $\begin{array}{l}12 \\
38\end{array}$ & $\begin{array}{l}9 \cdot 7 \\
6 \cdot 2\end{array}$ & $\begin{array}{l}1 \cdot 1 \\
0 \cdot 5\end{array}$ & $\begin{array}{l}2 \cdot 5 \\
1 \cdot 1\end{array}$ & $\begin{array}{l}96 \\
94\end{array}$ \\
\hline 9 & 41 & 3480 & $\mathbf{R h}$ incompatibility & 46 & $9 \cdot 0$ & 0.3 & $4 \cdot 5$ & 69 \\
\hline 10 & 40 & 3950 & $\mathbf{R h}$ incompatibility & 72 & $7 \cdot 8$ & $0 \cdot 1$ & $2 \cdot 1$ & 20 \\
\hline 11 & $\begin{array}{l}36 \text { (Small- } \\
\text { for-dates) }\end{array}$ & 2000 & ABO incompatibility & 10 & $14 \cdot 6$ & 0.3 & $2 \cdot 4$ & 82 \\
\hline 12 & 40 & 3490 & ABO incompatibility & 58 & $12 \cdot 8$ & $0 \cdot 1$ & $4 \cdot 6$ & 93 \\
\hline 13 & 40 & 3300 & $\begin{array}{l}\text { Hyperbilirubinaemia of unknown } \\
\text { origin }\end{array}$ & 78 & 3.4 & 0.03 & 6.4 & 92 \\
\hline 14 & 40 & 2820 & $\begin{array}{l}\text { Hyperbilirubinaemia of unknown } \\
\text { origin }\end{array}$ & 120 & $2 \cdot 6$ & 0.2 & $5 \cdot 7$ & 93 \\
\hline 15 & 40 & 2830 & $\begin{array}{l}\text { Hyperbilirubinaemia of unknown } \\
\text { origin }\end{array}$ & 111 & $4 \cdot 3$ & 0.06 & $5 \cdot 7$ & 96 \\
\hline 16 & 40 & 3200 & $\begin{array}{l}\text { Hyperbilirubinaemia of unknown } \\
\text { origin }\end{array}$ & 85 & $5 \cdot 6$ & 0.1 & $1 \cdot 6$ & 98 \\
\hline
\end{tabular}

IS = Infective syndrome, newborns with clinical features suggesting infection, but no infection documented, HMD $=$ hyaline membrane disease. 


\section{Patients and methods}

16 preterm and term babies had 23 ETs with 180 $\mathrm{ml} / \mathrm{kg}$ fresh ( $<60$ hours old) citrated blood (Table). In all of the severely ill newborn babies (Cases 1-8), ET followed earlier transfusions and was combined with chemotherapy (gentamicin, ampicillin, and cloxacillin). Blood samples were obtained from the donor before ET, and then from the baby at the beginning, at one-third and at two-thirds of the ET volume, and at the end of ET.

Leucocytes were isolated from heparinised blood on a Dextran 500 (Urografin) density gradient according to Böyum (1968). NBT reduction was tested, as previously described (Rubinstein and Pelet, 1973), for spontaneous and maximum capacity after stimulation with antigen-antibody complexes (normal human serum and sheep antitotal human serum, Behring). The opsonisation index was determined for the infant's and the donor's serum $(2 \cdot 5 \%)$, using the method of Soothill and Harvey (1976). Leucocytes were incubated in the presence of serum with yeast particles for 30 minutes at $37^{\circ} \mathrm{C}$. After low-speed centrifugation, one drop of the pellet was dried on a slide and stained with May-Grünewald-Giemsa. The greatest number of yeast particles per granulocytes was 8. As the aim of this study was to find out the effect of ET on granulocyte function, each newborn baby was classified according to the degree of his granulocytic dysfunction and that of the donor.

Statistical analysis used Student's $t$ test.

\section{Results}

Opsonisation index. This was $4 \cdot 88 \pm 0.26$ in 25 of the 27 donors. In the remaining 2 donors (Cases 7 and 9) it was extremely low $(<1)$ and only in ET with blood from them was there a decline in the opsonic activity of the baby's blood (from $6 \cdot 3$ and $4 \cdot 5$, to 0.7 and $1 \cdot 7$ ). In 15 ETs the index was initially similar in blood from the donor and patient and no change occurred after ET $(4 \cdot 56 \pm 0 \cdot 31$, to $4 \cdot 62 \pm 0 \cdot 31$ ). In 5 ETs in 5 patients (Cases 2a, $3 a, 5,8 b, 16)$ a low opsonisation index was improved by ET with donor blood of a normal index (Fig. 1).

Granulocytes from 9 patients were tested for uptake of yeast particles in autologous and donor sera (Fig. 2). In 11 ETs both sera gave identical results. In 4 ETs in 4 children (Cases $2 a, 3 a, 8 b, 16$ ) there was a significantly lower opsonisation index when the infant's leucocytes were tested in autologous serum compared with donor's serum. This difference disappeared during ET. In 2 patients a lower opsonisation index was observed in the donor's

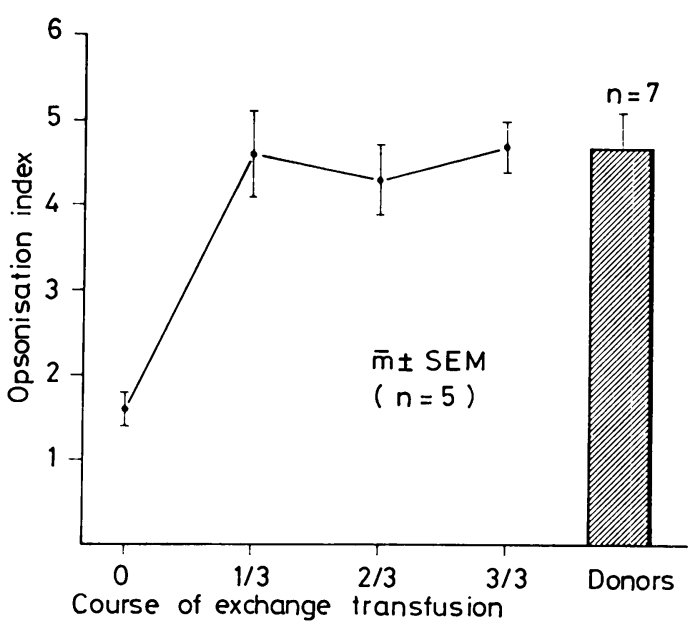

Fig. 1 Opsonisation test; infants deficient for yeast opsonisation transfused with donor blood with normal yeast opsonisation.

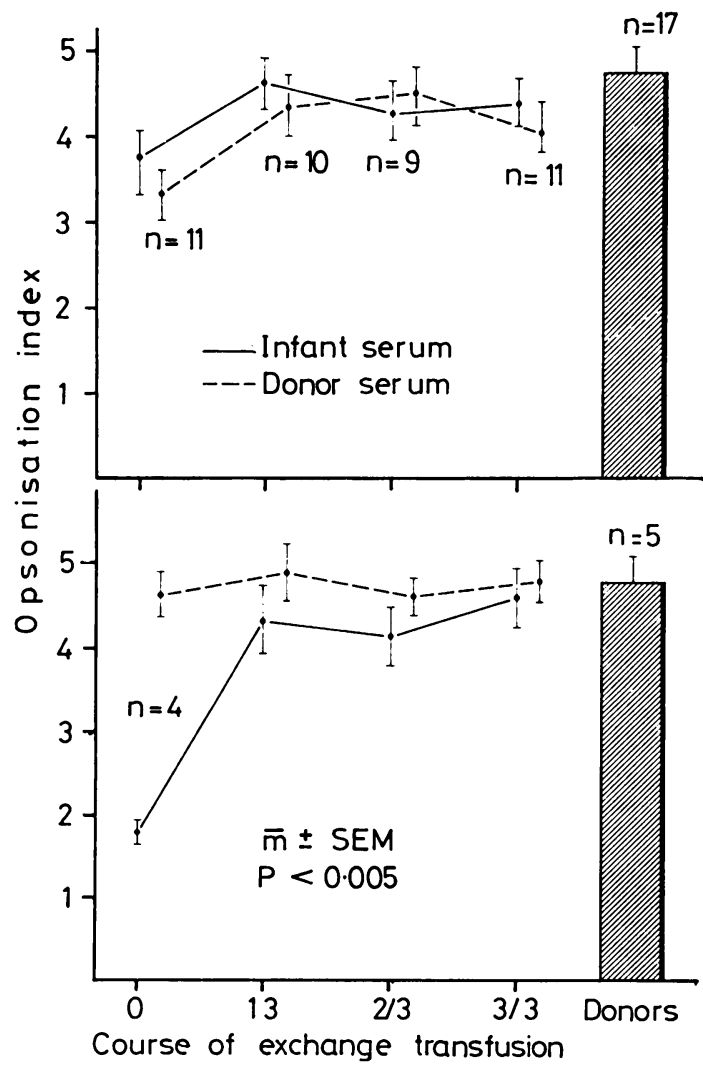

Fig. 2 Opsonisation test performed on the sera from the baby and donor. 
serum compared with autologous serum. This, however, did not affect the opsonisation index after ET.

Spontaneous NBT reductive activity. Granulocytes showed a wide scatter, as was reported by Moro (1976). In one patient (Case 2) with septicaemia and sclerema, an initial ET with blood containing granulocytes with a low maximum NBT reductive capacity caused no change in the infant's granulocyte spontaneous reduction, while ET with granulocytes of a high maximum NBT reductive capacity improved the infant's granulocyte spontaneous function (Fig. 3).

Maximum NBT reductive capacity. Granulocytes were tested in donor blood and in every baby except one (Case 1). Granulocytes from $13(52 \%)$ donors exhibited normal values $(89 \pm 2.6 \%), 8 \quad(32 \%)$ donors had moderately decreased values $(66 \pm$ $5.6 \%)$, and $3(16 \%)$ donors had a much depressed NBT reductive capacity $(26 \pm 6 \%)$. If the donor's granulocytes were normal or slightly depressed for this parameter, no change in the NBT reductive capacity was detected in the infant's blood (Fig. 4). In 3 children with normal maximum reductive activity (Cases 2a, 6, 7), ET with granulocytes of low maximum NBT reductive capacity resulted in a

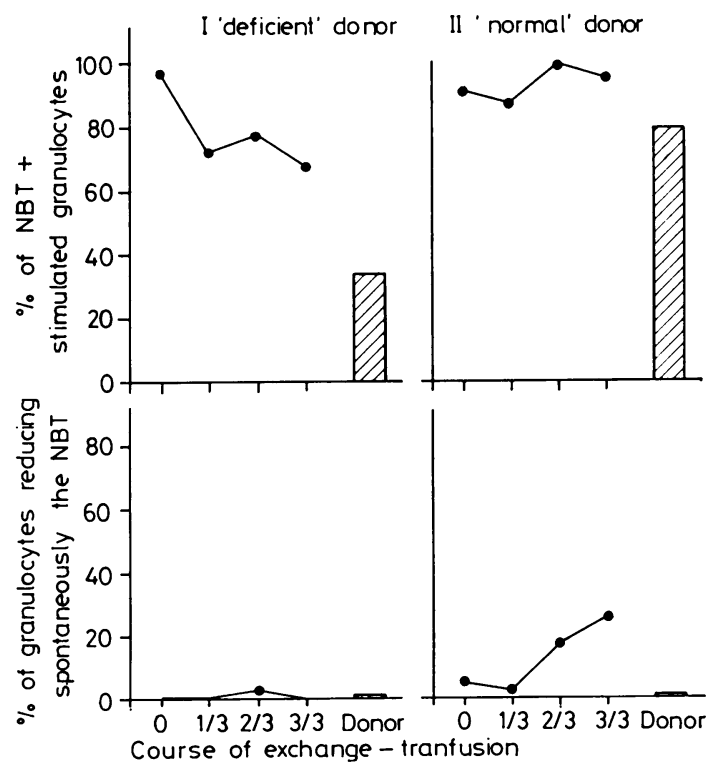

Fig. 3 (Cases $2 a$ and b) Infants' granulocyte spontaneous and maximum reductive capacity of NBT during exchange transfusion; a preterm baby with Escherichia coli septicaemia and sclerema receiving initially a 'deficient', then a 'normal' donor.

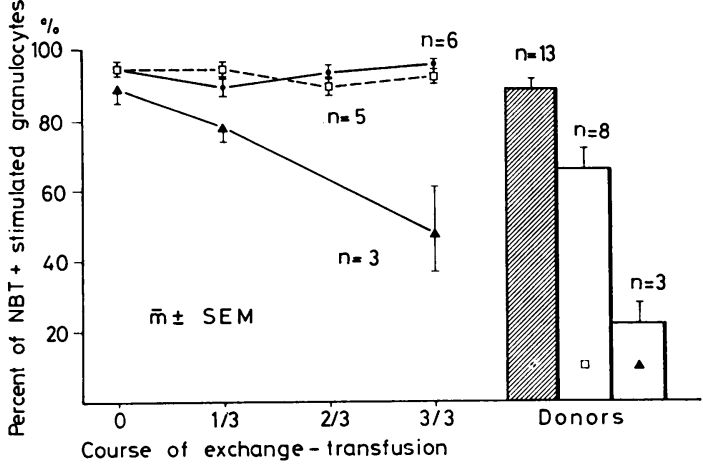

Fig. 4 NBT test; 'normal' infants transfused with 'normal' or 'deficient' donors.

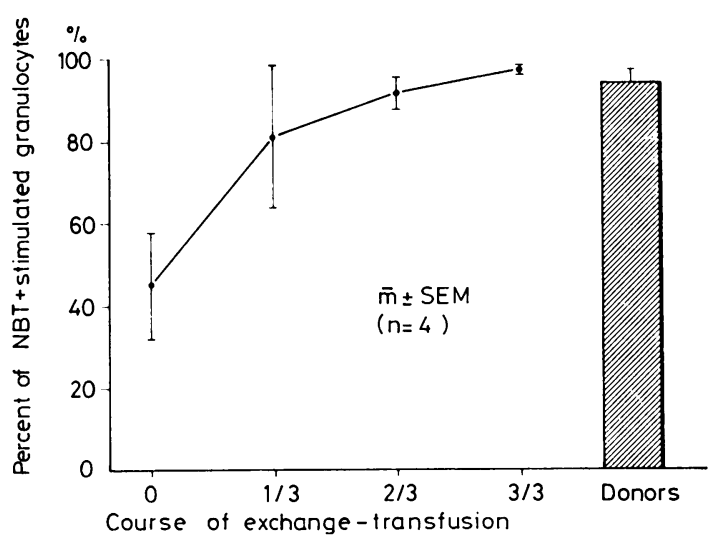

Fig. 5 NBT test; 'deficient' infants transfused with 'normal' donors.

decrease for this parameter in infant's blood obtained at the end of ET. Three babies (4 ETs) (Cases 2e, 3a, 3b, 10) who initially had very depressed NBT reductive capacities received granulocytes with normal reductive capacities and by the end of the ETs, the NBT reductive capacity was normal in all 3 patients (Fig. 5).

\section{Discussion}

Our aim was to determine the effects of exchange transfusion on the opsonic activity and granulocyte function of the newborn. Many abnormal immunological functions have been reported in healthy term and preterm babies, including decreased serum opsonic activity, low granulocyte NBT reductive capacity, and altered cell membrane stability (McCracken and Eichenwald, 1971; Stossel et al., 1973; Miller, 1975). But, as suggested by Soothill and 
Harvey (1976), we should consider the possibility that decreased opsonisation may be a congenital deficiency. Although the family of neither the baby nor the donor was studied, nor were 'deficient' recipients or donors further studied, an 18-months' follow-up of all newborns affected by septicaemia or other infective illnesses, led to no instance in which such congenital deficiency was suspected.

These data indicate that ET may improve such in vitro functions and may possibly modify the poor prognosis of infected infants. We have shown that donor ET blood with normal opsonisation for yeast, and/or donor granulocytes with normal maximum NBT reductive capacity, tended to improve the corresponding function in the newborn baby's circulation. On the other hand, the use of donor blood which was deficient in these functions impaired the opsonic activity and/or the NBT reductive capacity of the recipient. Theoretically, the decrease in opsonins after ET could be due to the dilution of patient's serum with donor serum of low opsonic activity. The effects of ET on granulocyte function may be related to a different mechanism, since transfused granulocytes generally rapidly disappear from the circulation of the recipient, possibly due to clearance (in a positive case) or transfusion (in a negative one) of an inhibitor. It is possible, however, that their retention in the circulation of the newborn is prolonged.

If ET is used in the management of neonatal sepsis, special attention must be given to the immunological properties of such blood. The transfusion of blood with inadequate opsonic activity may prove to be detrimental as judged by a consequential diminution in the recipient's circulation.

A surprising finding was that half the samples of donor blood exhibited an abnormal opsonic and/or NBT reductive capacity of polymorphonuclear leucocytes. The most likely cause is that blood had been stored and then been incorrectly handled (McCullough et al., 1974). As it is impracticable to screen every blood sample for its granulocyte and opsonic function, fresh blood which has been stored at $4^{\circ} \mathrm{C}$ for no longer than 12 hours should be used.

The clinical importance of correcting these immunological functions by means of ET has yet to be determined on a larger scale. Our initial studies show that the course of neonatal sepsis with sclerema neonatorum may be altered by ET.
We thank Professor D. Danks (Melbourne) and Professor A. Rubinstein (New York) for reviewing the manuscript, and Miss A. Vienny for technical assistance.

\section{References}

Böyum, A. (1968). Isolation of leukocytes from human blood. Further observations. Scandinavian Journal of Clinical and Laboratory Investigations, 21, Supplement 97, 31-50.

Davis, A. T., Blum, D. M., and Quie, P. G. (1971). Studies of opsonic activity for $E$. coli in premature infants after blood transfusion. In Proceedings of the Meeting of the Society for Pediatric Research, New Jersey, 1971, p. 233.

McCracken, G. H., and Eichenwald, H. F. (1971). Leukocyte function and the development of opsonic and complement activity in the neonate. American Journal of Diseases of Children, 121, 120-126.

McCullough, J., Carter, J. S., and Quie, P. G. (1974). Effects of anticoagulants and storage on granulocyte function in bank blood. Blood, 43, 207-217.

Miller, E. M. (1975). Developmental maturation of human neutrophil motility and its relationship to membrane deformability. In Phagocytic Cell in Host Resistance, pp. 295-307. Edited by A. J. Bellanti and H. D. Dayton. Raven Press: New York.

Moro, M. (1976). La réduction du nitrobleu de tetrazolium par les granulocytes dans la période néonatale. Thèse, Université de Lausanne.

Prod'hom, L. S., Choffat, J-M., Frenk, N., Mazouni, M., Relier, J-P., and Torrado, A. (1974). Care of seriously ill neonates with hyaline membrane disease and with sepsis (sclerema neonatorum). Pediatrics, 53, 170-181.

Rubinstein, A., and Pelet, B. (1973). Letter: False-negative NBT tests due to transient malfunction of neutrophils. Lancet, $1,382$.

Soothill, J. F., and Harvey, B. A. M. (1976). Defective opsonisation. A common immunity deficiency. Archives of Disease in Childhood, 51, 91-99.

Stossel, T. P., Alper, C. A., and Rosen, F. S. (1973). Opsonic activity in the newborn; the role of properdin. Pediatrics, 52, 134-137.

Torrado, A., Mazouni, M., and Prod'hom, L. S. (1974). L'exsanguino-transfusion comme moyen thérapeutique dans les sepsis néonatales compliquées de sclérème (abstract). Helvetica paediatrica acta, Supplement 32, 29-30.

Xanthou, M., Nicolopoulos, D., Gizas, A., and Matsaniotis, N. (1973). The response of leukocytes in the peripheral blood during and following exchange-transfusion in the newborn. Pediatrics, 51, 571-574.

Xanthou, M., Xypolyta, A., Anagnostakis, D., EconomouMavrou, C., and Matsaniotis, N. (1975). Exchangetransfusion in severe neonatal infection with sclerema. Archives of Disease in Childhood, 50, 901-902.

Correspondence to Dr B. Pelet, Service de Pédiatrie, Centre Hospitalier Universitaire Vaudois, 1011 Lausanne, Switzerland.

Received 21 December 1978 